(c) American Dairy Science Association, 2003.

\title{
Biochemistry, Genetics, and Applications of Exopolysaccharide Production in Streptococcus thermophilus: A Review ${ }^{1}$
}

\author{
J. R. Broadbent, ${ }^{\star} \dagger$ D. J. McMahon, ${ }^{\star} \dagger$ D. L. Welker, ${ }^{\star} \ddagger$ C. J. Oberg, ${ }^{\star} \S$ and S. Moineau \\ *Western Dairy Center, Department of †Nutrition and Food Sciences and Department of łBiology \\ Utah State University, Logan 84322-8700 \\ $\S$ Department of Microbiology, \\ Weber State University, Ogden UT 84408-2506 \\ |Département de Biochimie et de Microbiologie \\ Université Laval, Québec, Canada, G1K 7P4
}

\begin{abstract}
Many strains of Streptococcus thermophilus synthesize extracellular polysaccharides. These molecules may be produced as capsules that are tightly associated with the cell, or they may be liberated into the medium as a loose slime (i.e., "ropy" polysaccharide). Although the presence of exopolysaccharide does not confer any obvious advantage to growth or survival of $S$. thermophilus in milk, in situ production by this species or other dairy lactic acid bacteria typically imparts a desirable "ropy" or viscous texture to fermented milk products. Recent work has also shown that exopolysaccharide-producing $S$. thermophilus can enhance the functional properties of Mozzarella cheese, but they are not phage-proof. As our understanding of the genetics, physiology, and functionality of bacterial exopolysaccharides continues to improve, novel applications for polysaccharides and polysaccharide-producing cultures are likely to emerge inside and outside the dairy industry. This article provides an overview of biochemistry, genetics, and applications of exopolysaccharide production in S. thermophilus.
\end{abstract}

(Key words: Streptococcus thermophilus, exopolysaccharide, lactic acid bacteria)

Abbreviation key: $\mathbf{C P S}$ = capsular exopolysaccharide, $\mathbf{C P S}^{+/-}=$ability (+) or inability (-) to produce capsular exopolysaccharide, EPS = exopolysaccharide, $\mathbf{E P S}^{+/-}=$ability (+) or inability (-) to produce capsular or secreted exopolysaccharide, $\mathbf{L A B}=$ lactic acid bacteria .

\section{INTRODUCTION}

Extracellular polysaccharides are produced by a great variety of bacteria, including lactic acid bacteria

Received May 10, 2002

Accepted June 25, 2002.

Corresponding author: J. R. Broadbent; Tel: (435) 797-2113, Fax: (435) 797-2379, e-mail: broadbnt@cc.usu.edu.

${ }^{1}$ Contribution number 7463 of the Utah Agricultural Experiment Station, Utah State University, Logan 84322-4810.
(LAB). These polymers may be assembled as capsular (CPS) polysaccharides that are tightly associated with the cell surface, or they may be liberated into the growth medium (i.e., "ropy" polysaccharide). The term exopolysaccharide (EPS) may be used to describe either type of extracellular polysaccharide (Sutherland, 1972). Bacterial EPS can be composed of one type of sugar monomer (homopolysaccharide) or consist of several types of monomers (heteropolysaccharide). Well-known examples of LAB homopolysaccharides include dextrans and glucans produced by Leuconostoc mesenteroides and Streptococcus mutans, respectively. Heteropolysaccharides are synthesized by many LAB, including Streptococcus thermophilus, Lactococcus lactis, and dairy Lactobacillus spp. (De Vuyst et al., 2001).

Production of EPS has not been shown to confer any obvious advantage to growth or survival of $S$. thermophilus in milk. However, in situ EPS production by this species or other LAB starters typically imparts a desirable "ropy" or viscous texture to fermented milk products (Hassan et al., 1996a, 1996b; Laws and Marshall, 2001). Because $\mathrm{EPS}^{+}$strains of $S$. thermophilus and Lactobacillus delbrueckii subsp. bulgaricus can reduce syneresis and enhance product texture and viscosity, these types of cultures are commonly used as a substitute for commercial stabilizers in yogurt manufacture (Cerning, 1995). Although use of $\mathrm{EPS}^{+} \mathrm{LAB}$ starters is far less common in cheese manufacture, recent work has shown that $\mathrm{EPS}^{+} S$. thermophilus can improve the functional properties of lowfat or part-skim Mozzarella cheese (Perry et al., 1997; Low et al., 1998; Petersen et al., 2000). Biotechnological advances in molecular and genetic analyses of bacterial EPS have sparked renewed interest in EPS production by $S$. thermophilus and other LAB. As understanding of the genetics, physiology, and functionality of LAB EPS continues to improve, novel applications for polysaccharides and $\mathrm{EPS}^{+}$cultures are likely to emerge inside and outside the dairy industry. In this communication, we examine current knowledge related to EPS production by S. thermophilus. 


\section{Heteropolysaccharide Structure and Biosynthesis}

Compositional and structural analyses have revealed that $S$. thermophilus EPS are primarily composed of galactose, glucose, and rhamnose, but N-acetyl-galactosamine, fucose, and acetylated galactose have also been identified in these molecules (Figure 1). As shown in Figure 1, the basic repeating structure of $S$. thermophilus EPS may vary considerably, and variability in the molecular mass of structurally identical polymers has also been reported (Faber et al., 1998).

In many cases, research interest in biosynthesis of bacterial heteropolysaccharides has been driven by the knowledge that these polymers played an important role in virulence (Roberts, 1996). Thus, EPS biosynthesis is relatively well defined in gram-negative pathogenic bacteria such as Escherichia coli, Salmonella, and Haemophilus influenza. In these gram-negative systems, assembly of the basic repeating unit occurs at the cytoplasmic membrane and involves sequential transfer of sugar nucleotide diphospho precursors to an isoprenoid lipid carrier, undecaprenyl phosphate (Sutherland, 2001). Once the basic repeating unit is assembled, the lipid-linked intermediates are usually translocated across the membrane and polymerized outside of the cell. Then, the EPS may be covalently linked to the cell surface to form a capsule, or released into the medium as slime.

Considerable effort has also been directed toward understanding cellular mechanisms for EPS assembly in pathogenic streptococci such as Streptococcus pneumoniae, Streptococcus pyogenes, and Streptococcus agalactiae (Garcia et al., 1997; Garcia and Lopez, 1997; Kolkman et al., 1997; Yother, 1999; Chaffin et al., 2000; Bender and Yother, 2001). As a whole, those studies have demonstrated that streptococci possess at least two distinct mechanisms for EPS production. Synthesis of simple EPS, like $S$. pyogenes hyaluronic acid or $S$. pneumoniae type 3 capsule (which have linear, disaccharide basic repeating units) does not include formation of lipid-linked intermediates, whereas production of more complex EPS does (Yother, 1999). Functional genetic studies and homology comparisons of EPS-related gene products from $S$. thermophilus and L. lactis strongly suggest that cellular mechanisms for EPS synthesis in these species are similar to streptococcal and gram-negative systems that require formation of lipidlinked intermediates (Stingele et al., 1996, 1999; van Kranenburg et al., 1997, 1999a, 1999b; Low et al., 1998; Bourgoin et al., 1999; Almiron-Roig et al., 2000; Broadbent et al., 2001; Germond et al., 2001). Work by Stingele et al. (1999) has shown that EPS biosynthesis in S. thermophilus Sfi6 involved a lipid carrier, upon which the sugar monomers that comprise the basic repeating unit are assembled. The first step is catalyzed by EpsE, a galactosyl-1-phosphate transferase that attaches galactosyl-phosphate to a lipid-phosphate carrier. This reaction is followed by the action of three other glycosyltransferases, termed EpsG, EpsI, and EpsF, which sequentially attach $\mathrm{N}$-acetylgalactosamine, glucose, and a branching galactose moiety to the basic repeating unit (Figure 2). Unfortunately, very little is known about EPS polymerization, translocation, or capsule formation in S. thermophilus or any other gram-positive bacteria (Roberts, 1996; Garcia and López, 1997). Amino acid homologies between enzymes involved in these processes in gram-negative and grampositive bacteria suggest that they occur via similar mechanisms, but this hypothesis awaits experimental confirmation.

Cellular EPS biosynthesis is, therefore, an energyintensive process that involves enzymes for production of sugar nucleotide precursors, a glycosyl-1-phosphate transferase that transfers the first sugar group onto a phosphorylated carrier lipid, one or more glycosyltransferases that sequentially add new sugar groups to the growing repeat unit, and additional enzymes that participate in eps gene regulation, membrane translocation, and polymerization/chain length determination functions (Cerning, 1990; Whitfield and Keenleyside, 1995). These reactions commonly involve additional proteins with functions that are not unique to this process. Examples include housekeeping enzymes involved in the synthesis of molecules, such as lipid carrier and sugar nucleotide precursors, that are required for the assembly of other glycan-containing polymers, like peptidoglycan, teichoic acids, and lipoteichoic acids (Sutherland, 1972; Whitfield and Keenleyside, 1995; Delcour et al., 1999).

As is the case with most LAB, the ability to produce EPS in S. thermophilus is both strain dependent and significantly affected by media and growth conditions (e.g., temperature, carbon:nitrogen ratio, $\mathrm{pH}$, etc.) In milk, for example, the amount of EPS produced by $S$. thermophilus may range from $50 \mathrm{mg}$ to $1.5 \mathrm{~g} / \mathrm{L}$ (Degeest et al., 2001a). While these yields are comparable to those obtained for EPS from other LAB, they are quite low when compared to production of dextran or xanthan gums (Degeest et al., 2001a). For this reason, there is considerable interest in the metabolic engineering of $S$. thermophilus and other "food-grade" LAB to enhance EPS production. Potential targets for this work include housekeeping enzymes whose product availability may be limiting to EPS.

As noted previously, the lipid carrier for EPS assembly in gram-negative bacteria is undecaprenyl phosphate, and participation of this molecule in EPS synthe- 
EU20: (Marshall et al., 2001a)

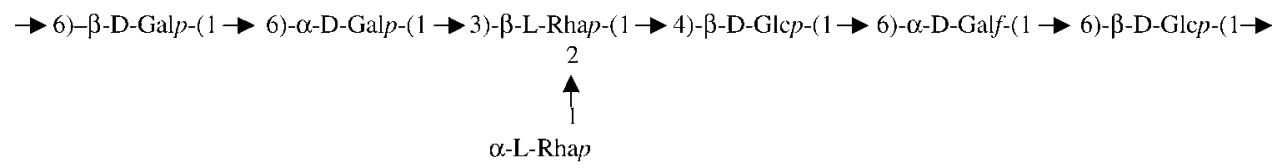

OR 901, Rs, Sts: (Bubb et al., 1997; Faber et al., 1998)

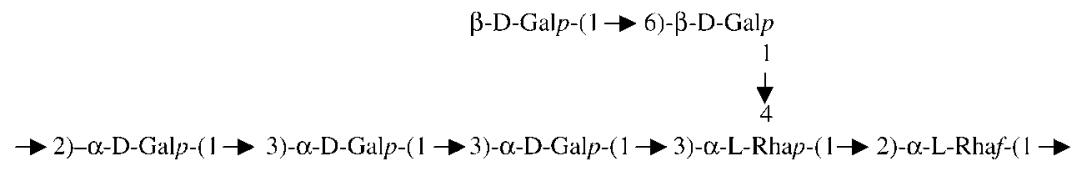

MR-1C: (Low et al., 1998)

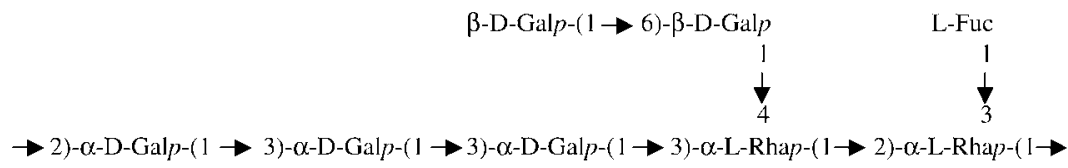

Sfi12: (Lemoine et al., 1997)

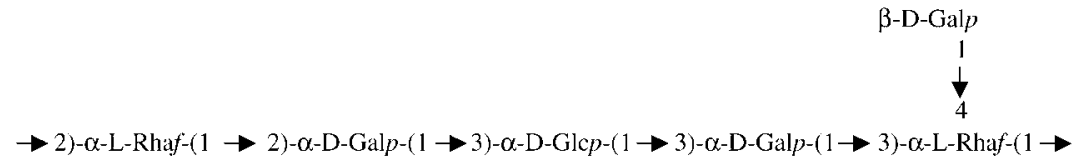

S3: (Faber et al., 2001)

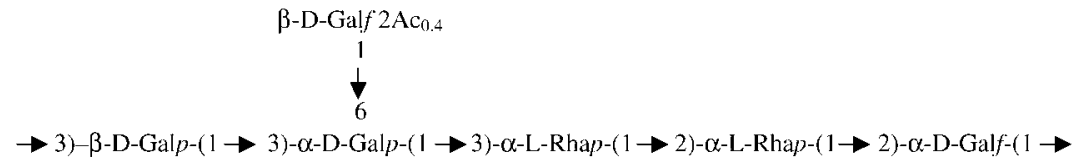

\section{CNCMI 733, CNCMI 734, CNCMI 735, Sfi6, Sfi20, IMDO1, IMDO2, IMDO3, NCFB 859, 21 :}

(Doco et al., 1990; Lemoine et al., 1997; Marshall et al., 200 lb; Stingele et al., 1996)

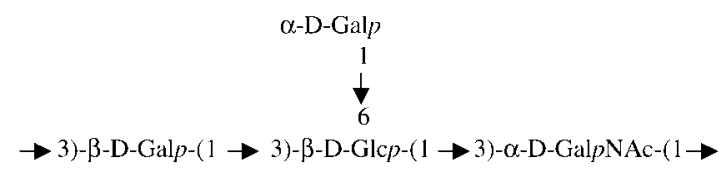

Sfi39, SY89, SY102: (Lemoine et al., 1997; Marshall et al., 2001b)

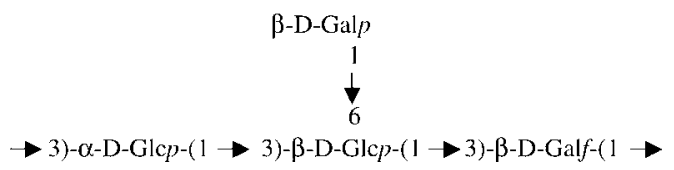

Figure 1. Basic repeating structures of Streptococcus thermophilus extracellular heteropolysaccharides. Fuc, fucose; Gal, galactose; GalNAc, N-acetyl-D-galactosamine; Glc, glucose; Rha, rhamnose; Ac, $O$-acetyl group; $p$, pyranose configuration; and $f$, furanose configuration. 


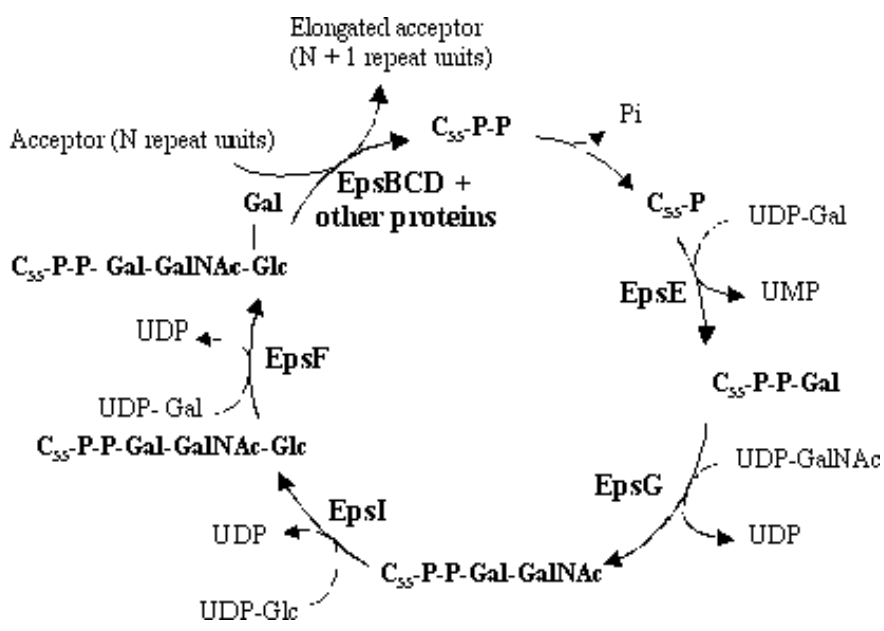

Figure 2. Model for assembly of the Streptococcus thermophilus Sfi6 exopolysaccharide basic repeating unit. Gal, galactose; GalNAc, N-acetyl-D-galactosamine; Glc, glucose; UDP, uridine-diphosphate. Adapted from Stingele et al. (1996, 1999).

sis by LAB may be significant because it is also required for assembly of peptidoglycan, teichoic acids, and lipoteichoic acids (Cerning, 1990; Delcour et al., 1999). Specifically, if the cellular concentration of undecaprenyl phosphate is limited, then competition for lipid carrier may be a key limiting factor in EPS biosynthesis. This hypothesis is supported by the frequent observation that incubation under conditions that stimulate bacterial growth and division reduce EPS production, while growth conditions which reduce the demand for new cell wall synthesis (such as incubation at a suboptimal temperature) tend to enhance EPS production (Sutherland, 1972; Cerning, 1995). Unfortunately, the identity of the lipid carrier for EPS assembly in Gram-positive bacteria has been elusive. It is interesting to note that EPS production in mesophilic LAB such as L. lactis typically follows the pattern described above, but production in S. thermophilus and other thermophilic LAB is often directly coupled to growth rate (i.e., maximal yield at maximal growth rate; De Vuyst et al., 2001). The latter observation and the finding that bacitracin (a compound that blocks undecaprenyl phosphate recycling) does not inhibit EPS production in $S$. thermophilus (Stingele et al., 1999), suggests that this species either utilizes an alternative carrier molecule or that undecaprenyl phosphate availability is not limiting.

Competition for sugar nucleotide precursors is another potential limitation to high EPS yields from $S$. thermophilus and other EPS-producing LAB (Boels et al., 2001). Many of the sugar nucleotide precursors used for EPS occur as intermediates in sugar catabolic pathways or, like undecaprenyl phosphate, are needed for the assembly of peptidoglycan and other glycan-containing cellular polymers (Poolman, 1993; Delcour et al., 1999). For example, UDP-glucose 4-epimerase (GalE) catalyzes the interconversion of UDP-galactose and UDP-glucose residues, each of which may be needed for assembly of $S$. thermophilus EPS and other cell polymers (Delcour et al., 1999; Stingele et al., 1999). This enzyme is also a component of the Leloir pathway for galactose catabolism (Whitfield and Keenleyside, 1995), but most strains of $S$. thermophilus are phenotypically galactose-negative. Galactose-fermenting mutants can be isolated after incubation in media with galactose as the sole carbohydrate source, however, and genes and low-level enzyme activities for GalE and all other Leloir pathway enzymes have been detected in this species (Thomas and Crow, 1984; Hutkins et al., 1985; Vaughan et al., 2001; Vaillancourt et al., 2002). These findings suggested that in $S$. thermophilus, the primary role for Leloir pathway enzymes is the production of sugar nucleotides for assembly of EPS and other polymers (Poolman, 1993). This hypothesis has since been confirmed for lactose-grown cells (Levander and Rådström, 2001).

Because low levels of sugar precursors may be a limiting factor on EPS yields, greater understanding of $S$. thermophilus metabolic flux in sugar metabolism may provide new strategies to enhance EPS production. Several researchers have demonstrated a correlation between EPS production and intracellular activities of enzymes from the Leloir and glycolytic pathways, but strain-to-strain variations are also apparent (Petit et al., 1991; Escalante et al., 1998; Degeest and De Vuyst, 2000; Levander and Rådström, 2001). Although the basis for these differences is not yet clear, Levander et al. (2002) recently showed such knowledge can be used to enhance EPS production in $S$. thermophilus by metabolic engineering of central carbon metabolism. In considering strategies for genetically enhancing EPS yields in $S$. thermophilus, it is also important to recognize that EPS production is an energy-intensive process, and that $S$. thermophilus have a limited number of catabolic pathways from which it can derive energy. Because EPS yields in most $S$. thermophilus are growth associated, efforts to dramatically increase production levels are likely to require novel strategies to enhance biomass production (Degeest et al., 2001a).

\section{Genetics of EPS Production in S. thermophilus}

Four distinct EPS gene clusters have been characterized to date in $S$. thermophilus (Stingele et al., 1996; Bourgoin et al., 1999; Almiron-Roig et al., 2000; Broadbent et al., 2001; Germond et al., 2001) (Figure 3), and recent work suggests a dozen or more unique eps clus- 
MR-1C, CNRZ368' : (Bourgoin et al., 1999; Welker and Broadbent, 2002c)

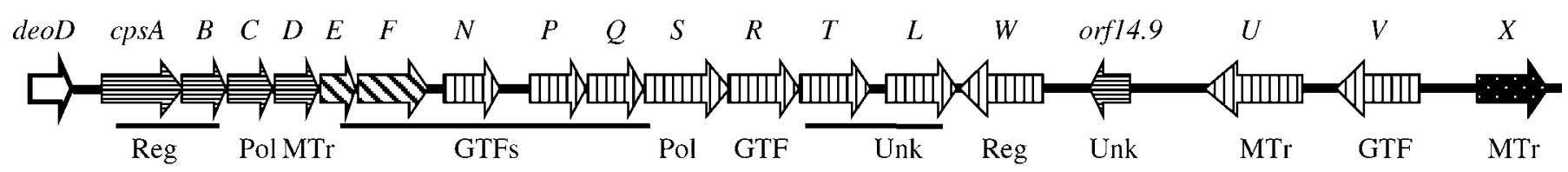

Sfi6 ${ }^{2}$, MR-2C, MTC360: (Stingele et al., 1996; Welker and Broadbent, 2002a and 2002b)

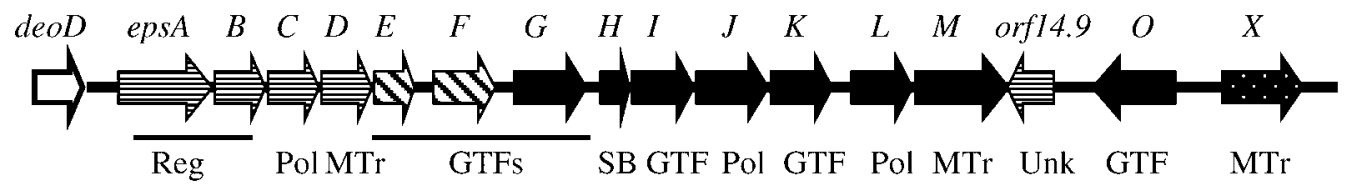

Sfi39 $^{3}$, F19186 ${ }^{4}$, MTC310: (Germond et al., 2001; I'Anson, 2002; Welker et al., 2002b)

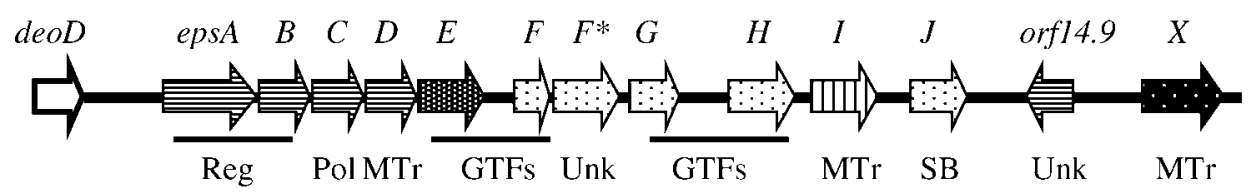

NCFB 2393: (Almirón-Roig et al., 2000)

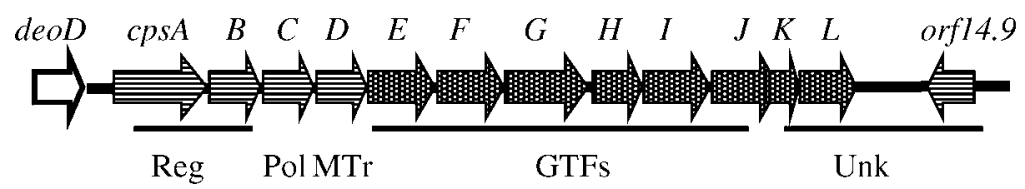

Figure 3. Physical maps of the genetic regions associated with exopolysaccharide biosynthesis in Streptococcus thermophilus. Bold letters identify strain names, and fill patterns identify genes that are at least $90 \%$ identical among strains. Putative or established functions for individual gene products are listed under each cluster. GTF, glycosyltransferase; MTr, membrane translocation; Pol, polymerization; Reg, regulation; SB, sugar biosynthesis; Unk, unknown. Maps are not to scale. ${ }^{1}$ Strain CNRZ368 does not produce exopolysaccharide due, presumably, to mutations in several cps genes (Bourgoin et al., 1999; Broadbent et al., 2001). ${ }^{2}$ Sequence data for the 3 ' region of the Sfi6 eps cluster does not extend beyond orf14.9 (Stingele et al., 1996). ${ }^{3}$ Sequence data for the 3 ' region of the Sfi39 eps cluster does not extend beyond orf14.9 (Germond et al., 2001). ${ }^{4}$ Sequence data for the 3 ' region of the FI9186 eps cluster does not extend beyond epsG (I'Anson, 2002).

ters may occur in this species (Rallu et al., 2002). Thus far, the distribution of regulatory and structural genes within each of these clusters shows a modular organization that is conserved in other Streptococcus spp. (Yother, 1999; Chaffin et al., 2000). Although the function of most EPS-related genes (currently designated eps or cps) and gene products are only inferred from sequence or structural homologies, the 5' region of each cluster appears to encode proteins involved in regulation of EPS synthesis, chain length determination, and membrane translocation. These open reading frames are followed by genes encoding the glycosyl-1-phosphate transferase and glycosyltransferases required for assembly of the basic repeating unit, and enzymes involved in repeat unit polymerization. Finally, the 3' end of these clusters typically contain genes for additional proteins involved in membrane translocation of the polymer subunits, and enzymes needed for the production of sugar nucleotide precursors (e.g., $N$-acetyl-Dgalactosamine; Stingele et al., 1996; Degeest et al., 2001b) that are unique to the EPS (i.e., not found in other cell polymers) (Chaffin et al., 2000).

The $S$. thermophilus eps clusters, like those of $S$. pneumoniae (Garcia and Lopez, 1997), are flanked by conserved regions that are not directly involved in CPS production (Figure 3). In S. thermophilus, the $5^{\prime}$ end of the cluster is preceded by $d e o D$, which encodes a homolog to purine nucleoside phosphorylase presumably involved in the biosynthesis and catabolism of nucleotides (Figure 3). In strain Sfi39, however, the intergenic region between $\operatorname{deo} D$ and epsA has been interrupted by transposition of a single copy of IS905 (Germond et al., 
2001). Several authors have suggested that the 3 ' end of the cluster is defined by orf14.9 (Stingele et al., 1996; Almiron-Roig et al., 2000; Germond et al., 2001), and this hypothesis was clearly supported for strain Sfi39 by heterologous expression of a structurally identical EPS in L. lactis (Germond et al., 2001). As shown in Figure 3, however, two of the four clusters characterized to date have genes encoding putative glycosyltransferases and other EPS-related enzymes downstream of orf14.9 (and in opposite orientation of other eps genes). Moreover, one of the downstream open reading frames in MR-1C (cpsU) is a homolog to the Sfi39 epsI gene located upstream of orf14.9 in the latter strain (Figure $3)$. These observations strongly suggest that some $S$. thermophilus eps clusters extend beyond orf14.9. Sequence extension beyond orf14.9 by our group has identified another gene, $c p s X$, whose presence downstream of the eps cluster is conserved in all strains examined to date (Broadbent et al., 2001; Welker and Broadbent, 2002a, 2002b; Welker et al., 2002b). The role, if any, of $\mathrm{CpsX}$ in polysaccharide synthesis is unknown, but this protein does show $50 \%$ similarity to a $S$. pneumoniae membrane protein that is genetically linked to a low molecular weight penicillin-binding protein in that species (Krauss and Hakenbeck, 1997). The region downstream of cps $X$ encodes a truncated $\beta$-galactosidase and a putative protein related to an $\mathrm{ABC}$ transport system (Welker and Broadbent, 2002a, 2002b, 2002c; Welker et al., 2002b).

The first four genes in the 5' region of $S$. thermophilus eps clusters, epsA-D, are highly conserved among this and other $\mathrm{EPS}^{+}$Streptococcus spp. (Cieslewicz et al., 2001) and appear to contribute regulation (epsA and eps $B$ ), polymerization (epsC), and membrane translocation (epsD) functions to EPS synthesis. Interestingly, these four genes are also found in many $S$. thermophilus strains that do not produce EPS (Stingele et al., 1996; Bourgoin et al., 1999; Pluvinet et al., 2000). Functional studies on epsA-D genes of $S$. thermophilus have not been reported, but the epsA gene product of this species and other streptococci show significant homology to $B a$ cillus subtilis LytR, a small, basic protein that negatively regulates transcription of the lyt $A B C$ operon encoding autolysin (Lazarevic et al., 1992). Inactivation of the epsA homolog in S. agalactiae, cpsIaA, confirmed that this gene is also involved in regulation of eps gene expression, but instead of increasing EPS production, the disruption mutant produced $24 \%$ less CPS and 2 to 3 fold less cps transcript than wild-type cells (Cieslewicz et al., 2001). Introduction of an inframe deletion mutation in cpsA also decreased CPS production in S. pneumoniae (Morona et al., 2000). These data suggest that CpsA acts as a transcriptional activator instead of an attenuator in streptococci. As noted by Cieslewicz et al.
(2001), streptococcal EpsA homologs differ from LytR in several features that may contribute to the distinct modes of action seen with each protein. For example, the N-terminal region of streptococcal EpsA homologs contain predicted membrane-spanning domains that are absent in LytR, and streptococcal EpsA proteins share conserved hydrophobic regions that have no counterpart in LytR. In addition, lytR and lytABC are transcribed from divergent promoters, whereas all streptococcal epsA genes appear to be transcribed as part of the eps operon (Lazarevic et al., 1992; Cieslewicz et al., 2001).

Like EpsA, streptococcal EpsB protein is also involved in regulation of EPS synthesis, but via an interaction with EpsC and EpsD (Bender and Yother, 2001; Morona et al., 2002). Inactivation of $\mathrm{CpsC}$ or $\mathrm{CpsD}$ in $S$. agalactiae reduced EPS chain length (i.e., the average molecular mass), which is consistent with the proposed role of these proteins in EPS polymerization and export (Cieslewicz et al., 2001). Streptococcal EpsC and EpsD proteins display sequence and structural homology to amino- and carboxy-terminal regions, respectively, of the $E$. coli autophosphorylating protein-tyrosine kinase Wzc, which also is involved in polymerization and export of capsular $\mathrm{K}$ antigen and colanic acid EPS (Figure 4; Vincent et al., 1999; Morona et al., 2000; Joly and Stingele, 2001; Wugeditsch et al., 2001). The E. coli Wzc and related proteins possess distinct transmembrane and nucleotide-binding domains. In Wzc, these domains are present in the same protein, but they may also be divided between two proteins such as streptococcal CpsC and CpsD homologs. Autophosphorylation of Wzc is required for CPS assembly, and this activity is likely regulated at the posttranslational level by a phosphotyrosine-protein phosphatase, Wzb (Vincent et al., 1999, 2000; Wugeditsch et al., 2001). Interestingly, the mechanism by which regulation occurs may differ even within a species; for example, phosphorylation of Wzc in E. coli enhances synthesis of capsular K antigen but inhibits production of colanic acid (Vincent et al., 2000; Wugeditsch et al., 2001). Like their functional homologs in streptococci, genes encoding Wzb and Wzc are found in the eps operon for the polymer whose synthesis is regulated by their activity (Rahn et al., 1999; Wugeditsch et al., 2001).

Functional studies in S. pneumoniae have shown that streptococcal EpsB, EpsC, and EpsD proteins are also required for CPS production and that this process is regulated by tyrosine phosphorylation and dephosphorylation of CpsD (Bender and Yother, 2001; Morona et al., 2000, 2002). As is the case for Wzc $P$ and colanic acid synthesis in $E$. coli, tyrosine phosphorylation of CpsD appears to negatively regulate CPS production in S. pneumoniae (Morona et al., 2000). In streptococci, 

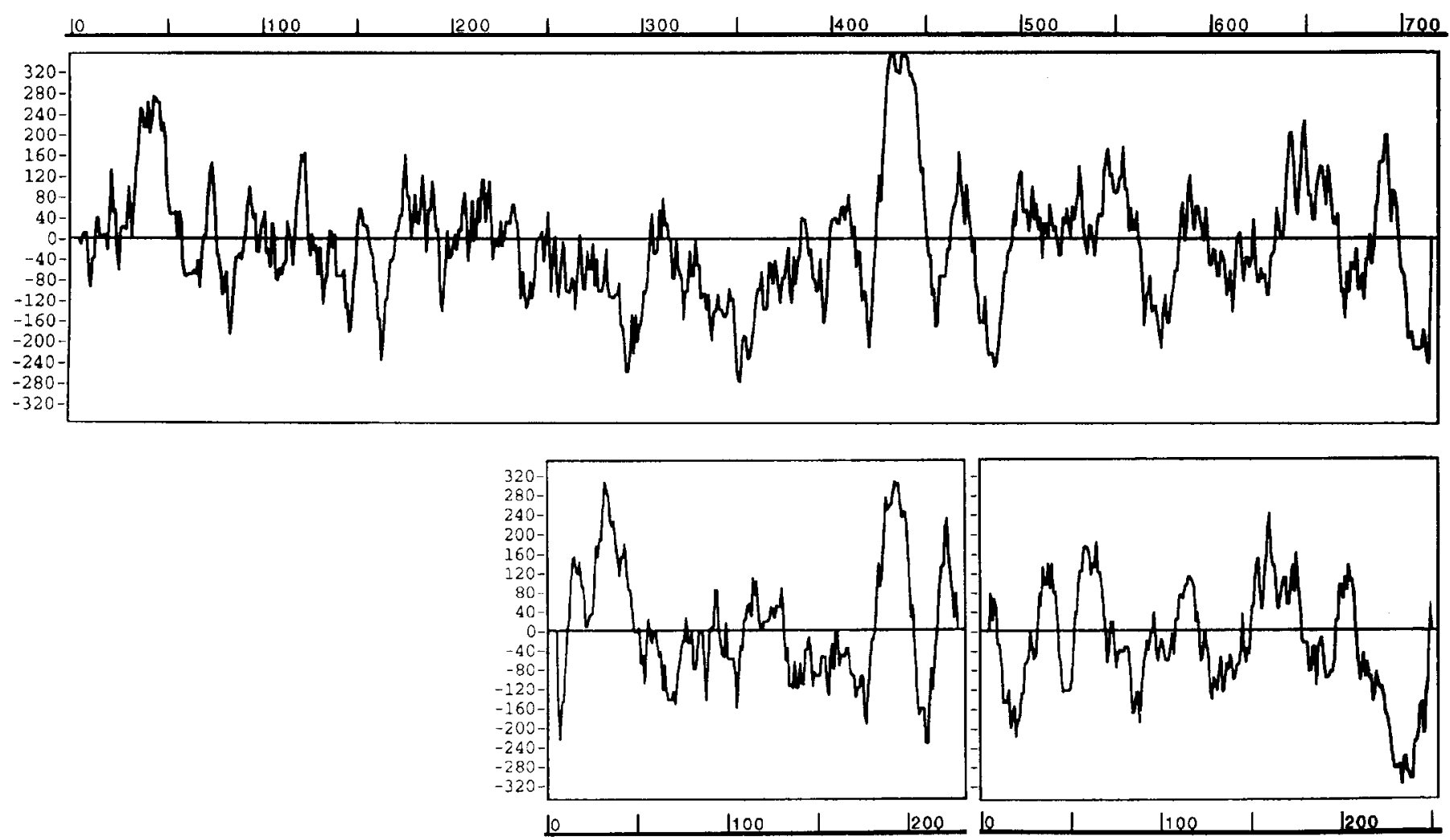

Figure 4. Kyte-Doolittle hydrophobicity plots for Escherichia coli Wzc (upper panel) and Streptococcus thermophilus MR-1C CpsC (lower left panel) and CpsD (lower right panel) proteins. The region between residues 60 and 227 of CpsC shows $20 \%$ identity and $44 \%$ similarity to Wzc residues 315 to 473 , and residues 24 to 228 of $\mathrm{CpsD}$ have $38 \%$ identity and $50 \%$ similarity to the region between residues 513 and 714 of Wzc. Numbered bars depict amino acid positions in the primary sequence of each protein.

dephosphorylation of $\mathrm{CpsD}$ is performed by $\mathrm{CpsB}$, a novel manganese-dependent phosphotyrosine phosphatase (Bender and Yother, 2001; Morona et al., 2000, 2002). More specifically, CPS production in S. pneumoniae involves a complex that includes, at minimum, CpsB, CpsC, CpsD, and ATP (Morona et al., 2000; Bender and Yother, 2001). Maximal levels of CPS biosynthesis/polymerization occur when ATP is bound to $\mathrm{CpsD}$, and ATP binding requires $\mathrm{CpsD}$ and $\mathrm{CpsC}$ interaction. However, autophosphorylation of $\mathrm{CpsD}$ tyrosine residues by bound ATP results in (or may occur as a consequence of) dissociation of $\mathrm{CpsD}$ from the complex and reduced CPS production. Finally, dephosphorylation of $\mathrm{CpsD}$ by $\mathrm{CpsB}$ regenerates active $\mathrm{CpsD}$ for complex formation and allows for increased CPS biosynthesis (Morona et al., 2000; Bender and Yother, 2001). Interestingly, CpsB also inhibits autophosphorylation of $\mathrm{CpsD}$, and the dual functions of this protein are suggestive of a central role in regulation of CPS biosynthesis (Bender and Yother, 2001). Although functional studies of S. thermophilus EpsB, EpsC, and EpsD proteins have not been performed, the existence of strains that produce comparable amounts of EPS with identical repeating units but different average molecular mass (Faber et al., 1998) strongly suggests that this species uses one or more mechanisms to regulate EPS polymerization and chain length. If streptococcal EpsB, EpsC, and EpsD perform similar functions in each species, then it may be possible to enhance the production level or molecular mass of $S$. thermophilus EPS by mutagenesis of the CpsD carboxy-terminal (YGX) motif required for phosphorylation (Morona et al., 2000). However, the subtleties noted above for Wzc $\sim \mathrm{P}$ regulation of CPS production in $E$. coli indicate that the role (if any) of EpsD phosphorylation in S. thermophilus must first be determined experimentally.

The fifth gene in $S$. thermophilus eps clusters, epsE, encodes a glycosyl-1-phosphate transferase that catalyzes the first step in assembly of the EPS basic repeating unit: addition of hexose-1-phosphate to the lipid-phosphate carrier (Stingele et al., 1999; AlmironRoig et al., 2000; Figure 2). Functional analyses have demonstrated that at least two enzymes of this type occur in $S$. thermophilus: a galactosyl-1-phosphate transferase $\left(M_{\mathrm{r}}=26,000\right)$ that attaches galactose-phosphate to phosphorylated lipid carrier and is represented 
by the EpsE protein of strain Sfi6 (Stingele et al., 1999), and a much larger $\left(M_{\mathrm{r}}=52,000\right)$ glucosyl-1-phosphate transferase that catalyzes glucose-phosphate addition to the lipid carrier and is represented by the NCFB $2393 \mathrm{CpsE}$ protein (Almiron-Roig et al., 2000). As is shown in Figure 3, DNA and predicted protein sequence alignments indicate the EpsE protein of strains MR$1 \mathrm{C}$ and Sfi39, respectively, are homologs ( $>90 \%$ amino acid identity) to the Sfi6 galactosyl-1-phosphate transferase and NCFB 2393 glucosyl-1-phosphate transferase. As might be expected from their mass discrepancies, the catalytic activity of $S$. thermophilus glycosyl1-phosphate transferases may differ in more ways than simple sugar-nucleotide specificity. For example, the WbaP protein of enteric bacteria is a bifunctional hexose-1-phosphate transferase that participates in the glycosyltransferase activity and in the release of the basic repeating unit from the lipid carrier (Wang et al., 1996). The domain associated with lipid carrier release is located in the amino-terminal region of $\mathrm{WbaP}$, whereas glycosyl-1-phosphate transferase activity is provided by the carboxy-terminal half of the protein. Almiron-Roig et al. (2000) showed that CpsE from NCFB 2393 and WbaP share topological similarity over their entire lengths and suggested that the NCFB 2393 glucosyl-1-phosphate transferase may also be a bifunctional protein. In contrast, the much smaller galactosyl1-phosphate transferase found in Sfi6 and MR-1C only shares homology to the carboxy-terminal region of $\mathrm{WbaP}$, and is, therefore, unlikely to participate in lipid carrier release. The latter observation suggests that in $S$. thermophilus strains encoding galactosyl-1-phosphate transferase, lipid carrier release may involve a second, as yet unidentified protein.

Genes downstream of epsE appear to encode glycosyltransferases, export/polymerization functions, sugar biosynthesis, and a few enzymes whose function is unknown. Genes encoding a variety of $\alpha$ - and $\beta$-glycosyltransferases have been identified in $S$. thermophilus and other LAB, and while clear functional assignments for LAB glycosyltransferases remain limited, the sugar specificity of many enzymes can be postulated from protein sequence comparisons (see Jolly and Stingele, 2001). Nonetheless, more work is needed to confirm these assignments and to establish the function of many other genes located in the 3' end of S. thermophilus eps clusters.

As is evident from the preceding discussion, many $S$. thermophilus eps genes are organizationally, structurally, and (presumably) functionally conserved in eps gene clusters from different $S$. thermophilus strains (Figure 3) and even among other streptococci and Gram-positive bacteria (Jiang et al., 2001; Jolly and Stingele, 2001). Sequence comparisons and functional studies of these genes and gene clusters are thus expected to provide great insight on the evolution, physiological role, and biology of EPS production in S. thermophilus and other LAB. In the dairy industry, such knowledge may ultimately allow for genetic engineering of novel EPS with predictable and unique value-added food properties. The functional and comparative genetic studies needed to attain these advances would be facilitated by implementation of a unified system for eps gene nomenclature in LAB. One avenue toward this goal would be to adopt the bacterial polysaccharide gene nomenclature system, wherein homologous genes are assigned the same symbol without regard to species or strain differences (Reeves et al., 1996; Jiang et al., 2001) (for current details, see http:// www.microbio.usyd.edu.au/BPDG/default.htm). By this approach, all of the $S$. thermophilus epsA-D (or cpsA-D) genes would be designated $w z g, w z h, w z d$, and $w z e$, respectively; and homologs to the NCFB $2393 \mathrm{cps} E$ and $c p s F$ genes would be termed $w c h A$ and $w c h F$, respectively (Reeves, 2002). In addition, protein sequence alignments and hydrophobicity profiles indicate Sfi6 epsM and MR-1C cpsU (designated as epsJ in strain Sfi39) genes encode homologs to the conserved "flippase" Wzx (Figure 5), while Sfi6 epsJ, MR-1C cpsS, and Sfi39 epsF* genes encode homologs to the conserved EPS polymerase Wzy (Figure 6). It is interesting to note that the absence of a $w z y$ homolog in the NCFB 2393 cps cluster suggests DNA sequence information for that strain's cluster may not be complete. Additional information related to the application of the bacterial polysaccharide gene nomenclature system in $S$. thermophilus is available from Welker and Broadbent (2002a and 2002c) and Welker et al. (2002b).

Finally, the $\mathrm{EPS}^{+}$phenotype in many lactic acid bacteria is unstable and may be permanently lost following repeated cell transfer or prolonged incubation (Cerning, 1990). The basis for this phenomenon, which is problematic to the dairy industry, has become more apparent through localization and characterization of eps gene clusters in $S$. thermophilus and other LAB. In most strains of $L$. lactis, for example, these genes are encoded by plasmid DNA (van Kranenburg et al., 1997, 1999b), which provides a simple genetic explanation (i.e., plasmid loss) for phenotype instability in these bacteria. In contrast, all eps gene clusters in $S$. thermophilus appear to be chromosomally encoded, so phenotype instability in this species is not as readily explained. The discovery that insertion sequence elements may lie within or adjacent to eps gene clusters in S. thermophilus, and that some strains display more generalized genomic instability, led Bourgoin et al. (1999) to suggest that one or both of these factors could contribute to $\mathrm{EPS}^{+}$instability in this species. The hy- 
A.

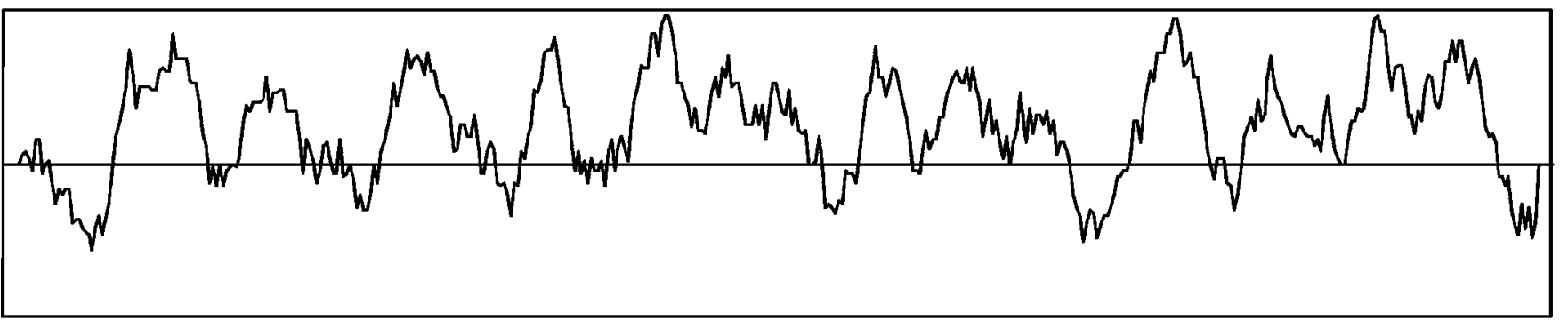

B.

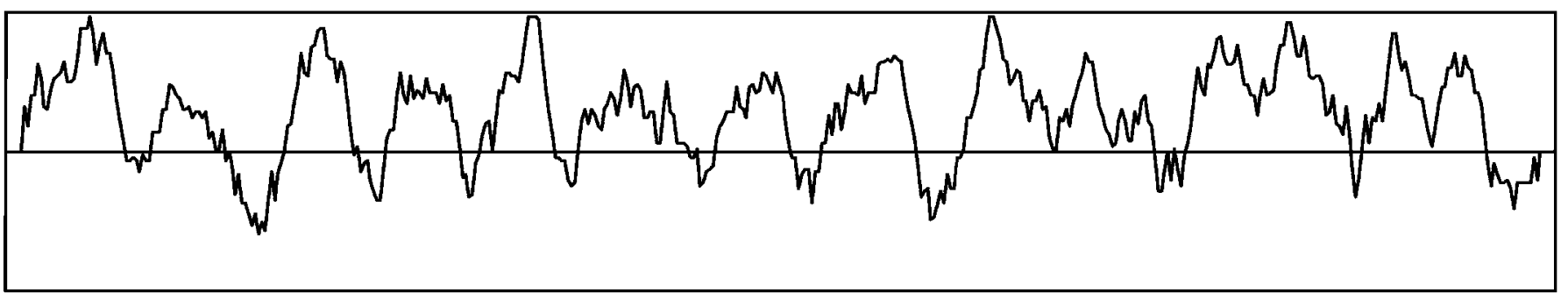

C.

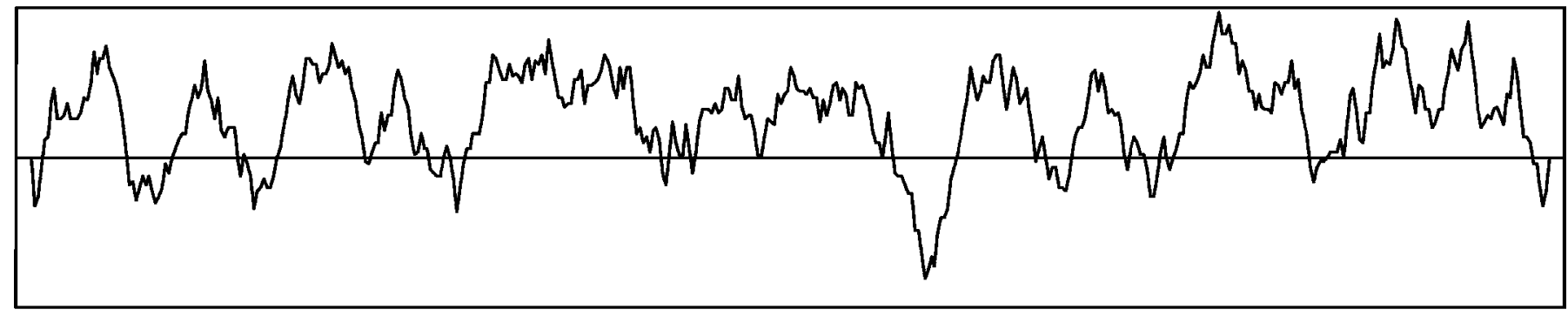

D.

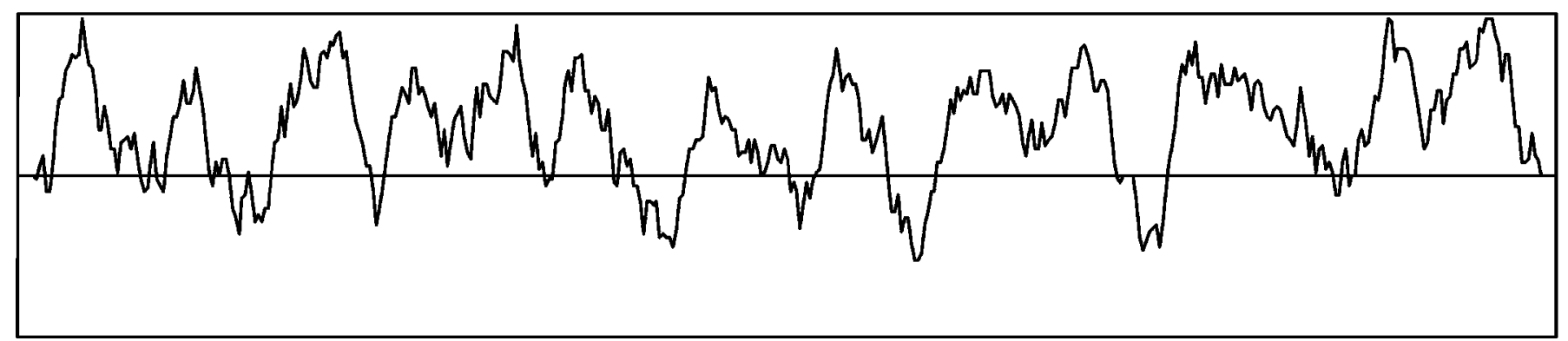

Figure 5. Kyte-Doolittle hydrophobicity plots for the conserved exopolysaccharide flippase Wzx of Escherichia coli (A) and Streptococcus pneumoniae (B), and for the deduced S. thermophilus protein EpsM from strain Sfi6 (C) and CpsU from MR-1C (D). Protein sequence alignments show the Sfi6 EpsM and MR-1C CpsU proteins are 56 and 57\% similar, respectively, to S. pneumoniae Wzx. 
A.

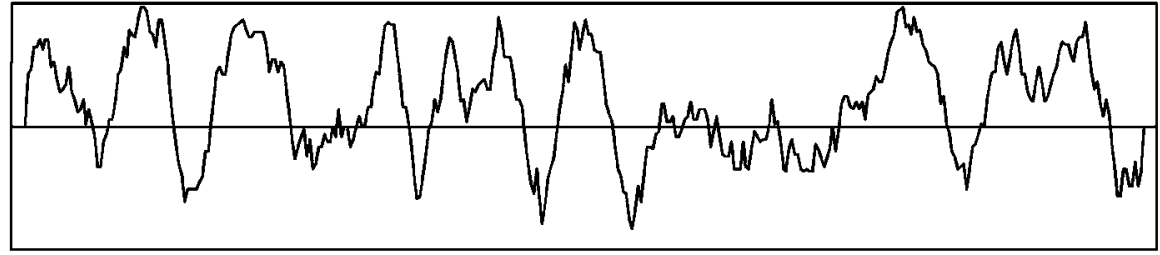

B.

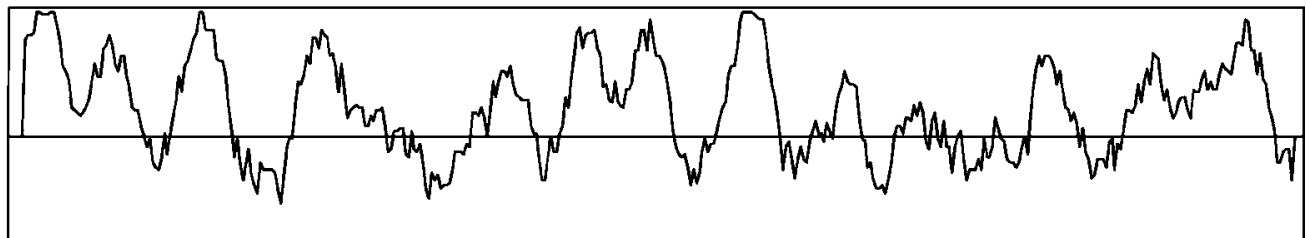

C.

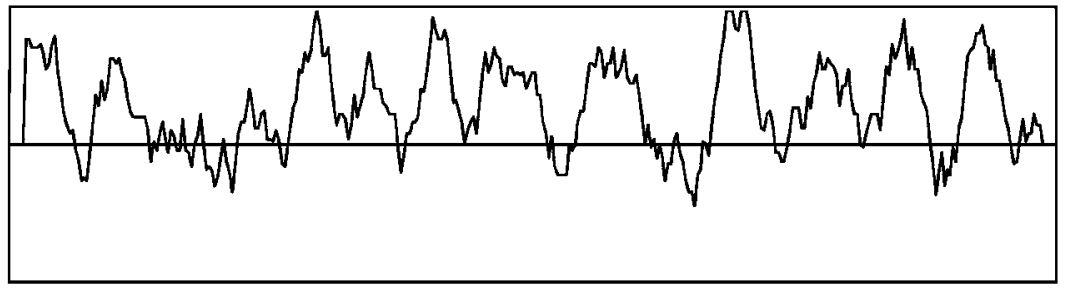

D.

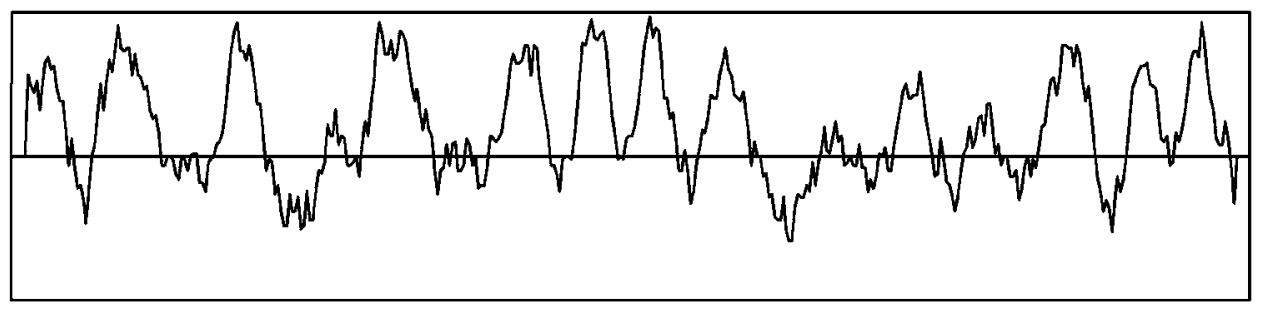

E.

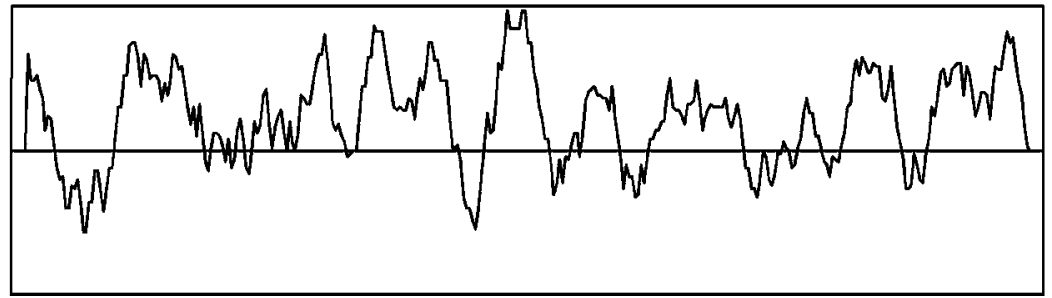

Figure 6. Kyte-Doolittle hydrophobicity plots for the conserved exopolysaccharide polymerase Wzy of Escherichia coli (A) and Streptococcus pneumoniae (B), and for the deduced S. thermophilus protein EpsJ from strain Sfi6 (C), CpsS from strain MR-1C (D), and Eps F* from strain Sfi39 (E). 


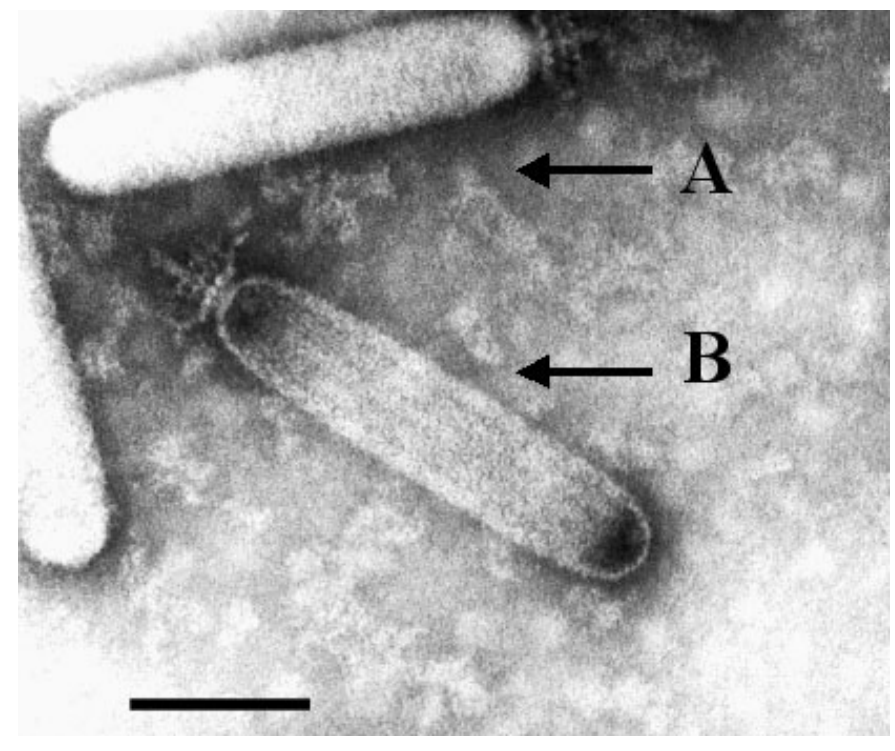

Figure 7. Transmission electron micrograph of Lactococcus lactis bacteriophage KSY1 (Podoviridae family). A, The phage head filled with DNA; B, the phage head is empty (no DNA). The bar represents $100 \mathrm{~nm}$.

pothesis that insertion sequence transposition and generalized genomic instability each contribute to EPS $^{+}$ instability now appears correct; the work of Germond et al. (2001) indicated that a spontaneous, nonropy mutant of S. thermophilus Sfi39 was produced by IS905 transposition into the epsF* gene of this strain (see Figure 3), and comparative genetic analysis of eps clusters from CNRZ368 (Bourgoin et al., 1999) and MR-1C (Broadbent et al., 2001) showed that general genomic instability was likely responsible for loss of the $\mathrm{EPS}^{+}$ phenotype in CNRZ368 (Welker et al., 2002a).

\section{Physiological Role of EPS}

In nature, bacterial EPS are thought to fulfill diverse functions that may include cell protection against toxic or limiting environments and other antagonisms, sequestering of essential cations, colonization, and in cellular recognition (Roberts, 1996; De Vuyst et al., 2001; Krinos et al., 2001; Looijesteijn et al., 2001). The excellent water-binding properties of EPS, for example, may protect bacteria in low-moisture environments, and capsular EPS can inhibit amoebic attack or phagocytosis (Sutherland, 1972; Kang and Cottrell, 1979; Roberts, 1996). The adhesive properties of EPS are of considerable interest because of the key role EPS plays in biofilm formation and dental caries pathogenesis (Cerning, 1990; Whitfield and Keenleyside, 1995). Since complex carbohydrates are implicated in a multitude of biological recognition reactions, EPS may also be in- volved with modulation of the immune system and/or host-pathogen interactions (Jolly and Stingele, 2001). Recently, Krinos et al. (2001) showed that the gramnegative human colonic microorganism, Bacteroides fragilis, is able to modulate its surface antigenicity by producing at least eight distinct capsular polysaccharides, and that the synthesis of these polymers is regulated in an on-off manner by the reversible inversion of DNA segments containing the gene promoters for CPS expression. This mechanism for generating surface diversity allows the organism to exhibit a wide array of distinct surface polysaccharide combinations, and may have implications on how bacteria are maintained in a specific ecological niche such as the intestinal tract (Krinos et al., 2001). One function that EPS production apparently does not provide is that of an energy reserve, since most $\mathrm{EPS}^{+} \mathrm{LAB}$ are unable to catabolize the polymers they produce (Cerning, 1990).

The protective effect of EPS against low-moisture environments led Petersen (2001) to investigate the effect of a $\mathrm{CPS}^{+}$phenotype in resistance of $S$. thermophilus to freezing and lyophilization. Cell counts collected before and after each challenge showed that viability of $S$. thermophilus MR-1C $\left(\mathrm{CPS}^{+}\right)$was numerically higher than that of its $\mathrm{CPS}^{-}$isogen, DM10, but the differences were not significant $(P>0.05)$. Interestingly, microscopic examination of rehydrated cells revealed that the mean chain length was reduced by lyophilization, and that the chain length of MR-1C did not decrease as much after freeze drying as did that of DM10. Even when chain length was taken into account, however, there was no significant difference $(P>0.05)$ in survivability between the two strains after lyophilization. Similar experiments with ropy $\mathrm{EPS}^{+}$and $\mathrm{EPS}^{-}$strains led the author to conclude that strain differences were more important than the presence or absence of EPS on resistance of $S$. thermophilus to freezing or lyophilization (Petersen, 2001).

\section{Bacteriophage Resistance}

Virulent bacteriophages, or phages for short, are the most significant cause of fermentation failures in the dairy industry worldwide (Moineau, 1999). As indicated previously, EPS are thought to protect cells against detrimental environmental conditions, and thick-layered CPS have been shown to protect bacteria against phage infection (Kang and Cottrell, 1979). However, the involvement of EPS in the phage infection process of LAB is still unclear.

For some gram-negative bacteria, the presence of EPS is essential to phage infection. In Vibrio cholera, for example, phages that specifically lyse $\mathrm{CPS}^{+}$strains have been isolated and used to identify variants that 
lacked CPS (Albert et al., 1996). Specific phages infecting $E$. coli strains that possess CPS have also been isolated (Dietz et al., 1986; Clarke et al., 2000; Scholl et al., 2001). For other gram-negative bacteria such as Rhizobium meliloti, EPS have been demonstrated to inhibit phage adsorption by coating the cells (Defives et al., 1996). A number of studies have suggested that EPS may also protect LAB cells against phage infection (Vedamuthu and Neville, 1986; Cerning, 1990; Moineau et al., 1996; De Vuyst and Degeest, 1999). Looijesteijn et al. (2001) showed that cell-associated EPS provided Lactococcus strains with a weak protection against phages, and Forde and Fitzgerald (1999a) showed that loosely bound EPS produced by some lactococcal strains slightly inhibited phage adsorption. The latter effect was presumably caused by obstruction of the interaction between the phage and the cell surface phage receptors (Forde and Fitzgerald, 1999a).

There are very few studies on the isolation and characterization of phages infecting $\mathrm{EPS}^{+} \mathrm{LAB}$ strains. Furthermore, to our knowledge, all such reports are related to the characterization of phages infecting $\mathrm{EPS}^{+}$Lactococcus strains. The first study was published more than $20 \mathrm{yr}$ ago and described the isolation of two lactococcal phages (Sozzi et al., 1978). However, these phages, as well as the interactions with their $\mathrm{EPS}^{+}$hosts, have not been characterized. The second study described the isolation of the lactococcal phage KSY1, which was isolated from the Finnish fermented ropy milk viili (Saxelin et al., 1979; Figure 7). Phage KSY1 is the reference phage for the lactococcal phage species that bears its name (Jarvis et al., 1991). This morphotype is very rare, as only two KSY1-like phages have been reported in lactococci (Saxelin et al., 1979, 1986). Saxelin et al. (1986) also reported the isolation and characterization of 13 morphological types of phages from viili. However, it is not known whether these phages infect EPS $^{+}$ strains.

Commercial $\mathrm{EPS}^{+}$Lactococcus strains are increasingly used by the dairy industry, and it is well documented that extensive use of a particular strain will lead to milk fermentation failures due to virulent phages. Indeed, Deveau et al. (2002) recently reported the isolation of eight distinct lactococcal phages infecting two $\mathrm{EPS}^{+}$strains used in 13 North American buttermilk factories. Some of these phages were isolated in only one dairy plant whereas others were found in several factories. The eight phages were classified within the 936 species (Siphoviridae family), which is one of the most common lactococcal phage species found in dairy plants (Moineau, 1999). Those researchers went on to cure the plasmid encoding the eps operon from the two phage-sensitive Lactococcus strains, and found that the cured-derivatives were still phage sensi- tive and the phages adsorbed to the same level on both $\mathrm{EPS}^{+}$and EPS ${ }^{-}$strains (Deveau et al., 2002). Deveau et al. (2002) also determined the monosaccharide composition of the polymer produced by phage-sensitive and phage-insensitive $\mathrm{EPS}^{+}$L. lactis strains. Similar sugar composition was found in EPS from both groups of strains. Taken together, these results indicate that: 1) $\mathrm{EPS}^{+}$lactococcal strains can be infected by phages in commercial applications such as buttermilk; 2) these phages are not fundamentally distinct from the phages infecting EPS $^{-}$strains used for the manufacture of most cheeses; 3 ) the presence of EPS is not necessary for phage infection; 4) in some strains, EPS clearly does not confer a phage resistance phenotype; and 5) sugar composition of the EPS has no effect on phage sensitivity.

We have also tested the phage sensitivity of the CPS ${ }^{+}$ $S$. thermophilus strain MR-1C as well as a $\mathrm{CPS}^{-}$derivative of MR-1C, strain DM10 (Moineau et al., 2002). Both strains were sensitive to three phages, Q1 and Q3 (Moineau et al., 1995) as well as phage Sfil1 for which the complete genomic sequence is now available (Lucchini et al., 1999). These three phages are classified within the pac-type group of $S$. thermophilus phages (Siphoviridae family, LeMarrec et al., 1997). These results indicate that the MR-1C CPS is not sufficient to protect those cells against these three phages and that it was not required for phage infection.

It remains to be seen whether the structure of some EPS produced by LAB could be involved in phage sensitivity or insensitivity. For example, it is known that the lactococcal phage infection process starts by the adsorption of the phage tail to a carbohydrate component such as galactose and rhamnose on the cell wall (for a review, see Forde and Fitzgerald, 1999b). EPS produced by $S$. thermophilus and other LAB are known to contain these sugars (Figure 1). It is, therefore, tempting to speculate that, in some cases, EPS could serve as a "decoy" for phage adsorption. Moreover, EPS production could increase the viscosity of the medium, and this molecular crowding could slightly inhibit the spread of the phage infection. It is also possible that the phage insensitivity reported in the literature for some $\mathrm{EPS}^{+}$LAB strains (Moineau et al., 1996) may simply be related to the absence of specific phage receptors on the cell surface of these strains. Nonetheless, it is now clear that processors cannot rely solely on EPS production to protect starter cultures against phage attack.

\section{Applications in Yogurt and Fermented Milks}

Incorporation of EPS or $\mathrm{EPS}^{+}$cultures in dairy foods can provide viscosity, stability, and water-binding func- 
tions (De Vuyst and Degeest, 1999) that may contribute positively to the mouth-feel, texture, and taste perception of fermented dairy products (Duboc and Mollet, 2001). For many years, European processors have exploited the differences among ropy $\mathrm{EPS}^{+} \mathrm{LAB}$ to produce a variety of fermented milks with unique properties (Cerning, 1995). Dairy processors have also utilized $\mathrm{EPS}^{+}$starter cultures to control syneresis in yogurt, and this practice is particularly widespread in countries where the addition of plant- or animal-derived stabilizers is prohibited (Cerning, 1995). The latter application is also important in light of modern consumer preferences for products with lower sugar and fat levels, and with fewer food additives.

Yogurt manufacture remains the most important commercial application for EPS ${ }^{+}$LAB in dairy foods, and several investigators have studied the impact of $\mathrm{EPS}^{+}$starters on the physical properties of yogurt. Hassan et al. (1996a) found that both ropy- and nonropyencapsulated $\left(\mathrm{CPS}^{+}\right)$strains of $S$. thermophilus increased yogurt viscosity more than nonropy-nonencapsulated (i.e., EPS ${ }^{-}$) strains. Additionally, ropy (slimeproducing) strains produced a more stretchable yogurt than nonropy encapsulated strains. When "yield stress" was measured (the force necessary to initiate flow), yogurt made with a nonropy $\mathrm{CPS}^{+}$strain had lower values than yogurt made using an EPS ${ }^{-}$strain. Rawson and Marshall (1997) also found that ropy starter bacteria increased yogurt viscosity, but firmness or elasticity was not always increased. The same study also found that yogurt made with a nonropy $S$. thermophilus and a ropy $L$. debrueckii ssp. bulgaricus recovered its viscosity more rapidly after destructive testing than yogurt made from two ropy cultures. The authors (Rawson and Marshall, 1997) suggested that this effect was due to EPS interference with protein bonding, which led to the formation of larger voids within the protein matrix.

Other studies indicated nonropy $\mathrm{CPS}^{+}$strains of $S$. thermophilus bound more water in yogurt than EPS ${ }^{-}$ strains, but ropy strains bound even more water than $\mathrm{CPS}^{+}$strains (Hassan et al., 1996b). As expected, increased levels of water binding made the yogurt less susceptible to syneresis. Both ropy and nonropy $\mathrm{CPS}^{+}$ strains bound sufficient additional water to affect yogurt texture. Stirred yogurt products possess a smooth, creamy texture, and are made by mild homogenization of yogurt coagulum after fermentation. The presence of EPS in stirred-type yogurt makes the product less susceptible to mechanical damage from pumping, blending, and filling machines (Robinson, 1981; De Vuyst and Degeest, 1999). Mechanical processing steps also increase syneresis of the final product, but use of EPS $^{+}$cultures can help to control this defect (Duboc and Mollet, 2001).
Besides yogurt, other dairy products in which $S$. thermophilus EPS has been shown to affect product quality include sour cream and traditional fermented milks in Nordic countries. Adapa and Schmidt (1998) showed that less syneresis occurred in sour cream made with $S$. thermophilus strains that produced larger versus smaller CPS. Strains producing the larger CPS also imparted a higher apparent viscosity as well as greater adhesiveness and gumminess to sour cream, which increased the "stringy" nature of the product.

Ropy mesophilic LAB cocci are the dominant flora of Nordic ropy milk, but EPS ${ }^{+}$strains of $S$. thermophilus are used in some types to provide proper texture. Strains of $\mathrm{EPS}^{+} S$. thermophilus have also been isolated from kefir grains, where they are suggested to affect the texture of kefir (Duboc and Mollet, 2001). EPSproducing strains of $S$. thermophilus have even been used in an attempt to reduce freezing mortality when viable LAB are incorporated into frozen dairy desserts as a source of $\beta$-galactosidase (Hong and Marshall, 2001). These researchers found that encapsulated strains survived better than nonencapsulated strains after freezing and frozen storage at $-29^{\circ} \mathrm{C}$ for $16 \mathrm{~d}$.

Research shows that ropy $\mathrm{EPS}^{+}$and nonropy $\mathrm{CPS}^{+}$ strains of $S$. thermophilus can influence the rheological properties of soft set milk products, but each type may have different effects. Although the amount of polymer produced certainly affects milk viscosity, Tunier (1999) showed that the functional impact of EPS on milk products was largely determined by the polysaccharide's molar mass, monosaccharide composition, and linkage type. In addition, EPS interaction with milk proteins also helps determine the viscosity of a fermented product. The practical significance of these observations may be illustrated by the work of Faber et al. (1998) with S. thermophilus Sts and Rs. Strains Sts and Rs are ropy and non-ropy cultures, respectively, that produce polysaccharide with an identical heptasaccharide basic repeating unit (see Figure 1) but different average molecular mass. The two cultures also have the same effect on the milk protein-polysaccharide network, but stirred milk cultures of Rs appeared "thin and lumpy," whereas those of Sts looked "very thick" (Faber et al., 1998). Further characterization of EPS functionality, structure, and genetics will ultimately allow dairy processors to select or perhaps even construct $\mathrm{EPS}^{+}$cultures that impart unique and predictable properties to a particular food product.

\section{Application in Mozzarella Cheese}

While the application of $\mathrm{EPS}^{+}$starter lactic acid bacteria has been largely confined to the production of yogurt and fermented milks, some companies have used 
ropy strains to improve the texture and functionality of cheese (Pruss and Bahrs, 1981; Nauth and Hayashi, 1995). Interest in $\mathrm{EPS}^{+}$starters for cheesemaking has been restricted, however, by the fact that EPS often accumulates in the cheese whey, thereby increasing its viscosity. This outcome is undesirable because it retards the efficiency of membrane processing and slows whey protein concentration and drying processes (Petersen et al., 2000).

Consumer demand for reduced-fat foods has created interest in the development and manufacture of reduced-fat, low-fat, and nonfat Mozzarella cheese, but fat removal has several undesirable effects on cheese physical properties (McMahon et al., 1993). Specifically, Mozzarella cheese becomes tough and rubbery, more heat is required for melting, and the cheese loses pliability rapidly during cooling (Mistry and Anderson, 1993). Research has revealed that these properties are heavily influenced by cheese moisture level (McMahon and Oberg, 1998). Examination of cheese microstructure shows that in full fat or part-skim Mozzarella cheese, much of the water is contained in channels formed in the protein matrix by entrapped fat globules (McMahon et al., 1993, Oberg et al., 1993). Because there are very few fat globules to break up the protein matrix in low-fat Mozzarella, these channels become much narrower with less space available for water retention. This results in cheese with a lower moisture level (Oberg et al., 1993) and, as a consequence, a tough, rubbery texture and poor melt and stretch properties (McMahon and Oberg, 1998).

Because EPS have excellent water-binding properties, and moisture retention is vital to functionality in low fat cheese (McMahon and Oberg, 1998), Perry et al. (1997) investigated the influence of an EPS-producing starter pair on the moisture and melt properties of low fat (6\%) Mozzarella cheese. Each of the bacteria used in that study, S. thermophilus MR-1C and L. bulgaricus MR-1R, produced EPS. As predicted, low-fat Mozzarella cheese manufactured with MR-1C and MR-1R contained significantly $(P<0.05)$ more moisture and had better melting properties than cheese made with an EPS $^{-}$commercial starter pair (S. thermophilus TAO61 and Lactobacillus helveticus LH100). Subsequent work by Low et al. (1998) showed this effect was caused exclusively by $S$. thermophilus MR-1C, and that the waterbinding properties of this bacterium were imparted by its large CPS.

While the ability to enhance cheese yield (through increased moisture retention) and functionality are strong incentives to use EPS ${ }^{+}$cultures in Mozzarella cheese, concerns over EPS accumulation in cheese whey continue to limit commercial interest in $\mathrm{EPS}^{+}$cheese starters. However, it is important to recognize that while EPS accumulation in cheese whey may be expected from ropy starters, $\mathrm{CPS}^{+}$bacteria are less likely to affect whey viscosity because the polymer is covalently linked to the cell wall (Deng et al., 2000). Petersen et al. (2000) investigated the effect of capsular and ropy $\mathrm{EPS}^{+}$S. thermophilus starters on part-skim Mozzarella cheese and whey. They showed that cheese moisture levels were significantly higher in Mozzarella made with $\mathrm{EPS}^{+}$versus $\mathrm{EPS}^{-}$streptococci, but whey from cheese made with the ropy starter was significantly more viscous $(P<0.01)$ than whey from cheeses made with the $\mathrm{CPS}^{+}$or $\mathrm{EPS}^{-}$strains. More importantly, no significant difference was detected in the viscosity of 5fold concentrated whey from cheese made with $\mathrm{CPS}^{+}$ or a commercial EPS ${ }^{-}$starter (Petersen et al., 2000). These findings indicate that $\mathrm{CPS}^{+}$, but not ropy, $S$. thermophilus starter bacteria can be used to enhance Mozzarella cheese moisture level, yield, and melt properties without deleteriously affecting whey viscosity.

\section{CONCLUSIONS}

Fundamental understanding of EPS genetics and biosynthesis in S. thermophilus and other streptococci has increased considerably in recent years. Dozens of basic repeat unit structures have been described, the organization and function of numerous eps genes has been determined, and the molecular basis for structure-function relationships of EPS in food systems has begun to be elucidated. As this research continues, the dairy industry can expect to see more widespread application of EPS and $\mathrm{EPS}^{+}$cultures in ways that provide addedvalue and innovation to milk products for years to come.

\section{ACKNOWLEDGMENTS}

The authors acknowledge the important contributions of J. Ahlgren, R. Dave, D. Low, D. Perry, and B. Petersen to this work. We also thank P. Reeves and the Bacterial Polysaccharide Gene Database for assistance in standard nomenclature for $S$. thermophilus eps genes, K. Diallo and H.-W. Ackermann for providing the electron micrograph of bacteriophage KSY1, and H. Deveau for critical reading of this manuscript. This work was supported by grants from Dairy Management, Inc. (J. B.), the Natural Sciences and Engineering Research Council of Canada (S.M.), and the Utah Agricultural Experiment Station.

\section{REFERENCES}

Adapa, S., and K. A. Schmidt. 1998. Physical properties of low-fat sour cream containing exopolysaccharide-producing lactic acid bacteria. J. Food Sci. 63:901-903.

Albert, M. J., N. A. Bhuiyan, A. Rahman, A. N. Ghosh, K. Hultenby, A. Weintraub, S. Nahar, A. K. M. G. Kibriya, M. Ansaruzzaman, 
and T. Shimada. 1996. Phage specific for Vibrio cholerae O139 Bengal. J. Clin. Microbiol. 34:1842-1845.

Almiron-Roig, E., F. Mulholland, and M. J. Gasson. 2000. The complete cps gene cluster from Streptococcus thermophilus NCFB 2393 involved in the biosynthesis of a new exopolysaccharide. Microbiology 146:2793-2802.

Bender, M. H., and J. Yother. 2001. CpsB is a modulator of capsuleassociated tyrosine kinase activity in Streptococcus pneumoniae. J. Biol. Chem. 276:47966-47974.

Boels, I. C., R. van Kranenburg, J. Hugenholtz, M. Kleerebezem, and W. M. de Vos. 2001. Sugar catabolism and its impact on the biosynthesis and engineering of exopolysaccharide production in lactic acid bacteria. Int. Dairy J. 11:723-732.

Bourgoin, F., A. Pluvinet, B. Gintz, B. Decaris, and G. Guedon. 1999. Are horizontal transfers involved in the evolution of the Streptococcus thermophilus exopolysaccharide synthesis loci? Gene 233:151-161.

Broadbent, J. R., D. J. McMahon, C. J. Oberg, and D. L. Welker. 2001. Use of exopolysaccharide-producing cultures to improve the functionality of low fat cheese. Int. Dairy J. 11:433-439.

Bubb, W. A., T. Urashima, R. Fujiwara, T. Shinnai, and H. Ariga. 1997. Structural characterization of the exocellular polysaccharide produced by Streptococcus thermophilus OR 901. Carbohydr. Res. 301:41-50.

Cerning, J. 1990. Exocellular polysaccharides produced by lactic acid bacteria. FEMS Microbiol. Rev. 87:113-130.

Cerning, J. 1995. Production of exocellular polysaccharides by lactic acid bacteria and dairy propionibacteria. Lait 75:463-472.

Chaffin, D. O., S. B. Beres, H. H. Yim, and C. E. Reubens. 2000. The serotype of type Ia and III Group B streptococci is determined by the polymerase gene within the polycistronic capsule operon. J. Bacteriol. 182:4466-4477.

Cieslewicz, M. J., D. L. Kasper, Y. Wang, and M. R. Wessels. 2001. Functional analysis in type Ia Group B Streptococcus of a cluster of genes involved in extracellular polysaccharide production by diverse species of streptococci. J. Biol. Chem. 276:139-146.

Clarke, B. R., F. Esumeh, and I. S. Roberts. 2000. Cloning, expression, and purification of the K5 capsular polysaccharide lyase (KflA) from coliphage K5A: Evidence for two distinct K5 lyase enzymes. J. Bacteriol. 182:3761-3766.

Defives, C., M. Werquin, P. Mary, and J. P. Hornez. 1996. Roles of exopolysaccharides and lipopolysaccharides in the adsorption of the Siphovirus phage NM8 to Rhizobium meliloti M11S cells. Curr. Microbiol. 33:371-376.

Degeest, B., and L. De Vuyst. 2000. Correlation of activities of the enzymes $\alpha$-phosphoglucomutase, UDP-galactose 4-epimerase, and UDP-glucose pyrophosphorylase with exopolysaccharide biosynthesis by Streptococcus thermophilus LY03. Appl. Environ. Microbiol. 66:3519-3527.

Degeest, B., F. Vaningelgem, and L. De Vuyst. 2001a. Microbial physiology, fermentation kinetics, and process engineering of heteropolysaccharide production by lactic acid bacteria. Int. Dairy J. 11:747-757.

Degeest, B., F. Vaningelgem, A. P. Laws, and L. De Vuyst. 2001b. UDP-N-acetylglucosamine 4-epimerase activity indicates the presence of $N$-acetylgalactosamine in exopolysaccharides of Streptococcus thermophilus strains. Appl. Environ. Microbiol. 67:3976-3984

Delcour, J., T. Ferain, M. Deghorian, E. Palumbo, and P. Hols. 1999 The biosynthesis and functionality of the cell wall of lactic acid bacteria. Antonie van Leeuwenhoek 76:159-184.

Deng, L., D. L. Kasper, T. P. Krick, and M. R. Wessels. 2000. Characterization of the linkage between the type III capsular polysaccharide and the bacterial cell wall of group B Streptococcus. J. Biol. Chem. 275:7497-7504.

Deveau, H., M.-R. van Calsteren, and S. Moineau. 2002. The effect of exopolysaccharides on phage-host interactions in Lactococcus lactis. Appl. Environ. Microbiol. 68:4364-4369.

De Vuyst, L., and B. Degeest. 1999. Heteropolysaccharides from lactic acid bacteria. FEMS Microbiol. Rev. 23:153-177.
De Vuyst, L., F. De Vin, F. Vaningelgem, and B. Degeest. 2001. Recent developments in the biosynthesis and applications of heteropolysaccharides from lactic acid bacteria. Int. Dairy J. 11:687-707.

Dietz A., E. Andrejauskas, M. Messerschmid, and R. Hausmann. 1986. Two groups of capsule-specific coliphages coding for RNA polymerases with new promoter specificities. J. Gen. Virol. 67:831-838.

Doco, T., J.-M. Wieruszeski, and B. Fournet. 1990. Structure of an exocellular polysaccharide produced by Streptococcus thermophilus. Carbohydr. Res. 198:313-321.

Duboc, P., and B. Mollet. 2001. Applications of exopolysaccharides in the dairy industry. Neth. Milk Dairy J. 11:759-768.

Escalante, A., C. Wacher-Rodarte, M. Garcia-Garibay, and A. Farres. 1998. Enzymes involved in carbohydrate metabolism and their role on exopolysaccharide production in Streptococcus thermophilus. J. Appl. Microbiol. 84:108-114.

Faber, E. J., M. J. van den Haak, J. P. Kamerling, and J. F. G. Vliegenthart. 2001. Structure of the exopolysaccharide produced by Streptococcus thermophilus S3. Carbohydr. Res. 331:173-182.

Faber, E. J., P. Zoon, J. P. Kamerling, and J. F. G. Vliegenthart. 1998. The exopolysaccharides produced by Streptococcus thermophilus Rs and Sts have the same repeating unit but differ in viscosity of their milk cultures. Carbohydr. Res. 310:269-276.

Forde, A., and G. F. Fitzgerald. 1999a. Analysis of exopolysaccharide (EPS) production mediated by the bacteriophage adsorption blocking plasmid, pCI658, isolated from Lactococcus lactis ssp. cremoris HO2. Int. Dairy J. 9:465-472.

Forde, A., and G. F. Fitzgerald. 1999b. Bacteriophage defense systems in lactic acid bacteria. Antonie van Leeuwenhoek 76:89-113.

Garcia, E., C. Arrecubieta, R. Munoz, M. Mollerach, and R. Lopez. 1997. A functional analysis of the Streptococcus pneumoniae genes involved in the synthesis of type 1 and type 3 capsular polysaccharides. Microb. Drug Resist. 3:73-88.

Garcia, E., and R. Lopez. 1997. Molecular biology of the capsular genes of Streptococcus pneumoniae. FEMS Microbiol. Lett. 149:1-10.

Germond, J.-E., M. Delley, N. D'Amico, and S. J. F. Vincent. 2001. Heterologous expression and characterization of the exopolysaccharide from Streptococcus thermophilus Sfi39. Eur. J. Biochem. 268:5149-5156.

Hassan, A. N., J. F. Frank, K. A. Schmidt, and S. I. Shalabi. 1996a. Rheological properties of yogurt made with encapsulated nonropy lactic cultures. J. Dairy Sci. 79:2091-2097.

Hassan, A. N., J. F. Frank, K. A. Schmidt, and S. I. Shalabi. 1996b. Textural properties of yogurt made with encapsulated nonropy lactic cultures. J. Dairy Sci. 79:2098-2103.

Hong, S. H., and R. T. Marshall. 2001. Natural exopolysaccharides enhance survival of lactic acid bacteria in frozen dairy desserts. J. Dairy Sci. 84:1367-1374.

Hutkins, R. H., H. A. Morris, and L. L. McKay. 1985. Galactokinase activity in Streptococcus thermophilus. Appl. Environ. Microbiol. 50:777-780

I'Anson, K. J. A. 2002. Sequence of the exopolysaccharide gene cluster of Streptococcus thermophilus FI9186. Genbank accession number AJ272341.

Jarvis, A. W., G. F. Fitzgerald, M. Mata, A. Mercenier, H. Neve, I B. Powell, C. Ronda, M. Saxelin, and M. Teuber. 1991. Species and type phages of lactococcal bacteriophages. Intervirology 32:2-9.

Jiang, S.-M., L. Wang, and P. R. Reeves. 2001. Molecular characterization of Streptococcus pneumoniae type $4,6 \mathrm{~B}, 8$, and $18 \mathrm{C}$ capsular polysaccharide gene clusters. Infect. Immun. 69:1244-1255.

Jolly, L., and F. Stingele. 2001. Molecular organization and functionality of exopolysaccharide gene clusters in lactic acid bacteria. Int. Dairy J. 11:733-745.

Kang, K. S., and I. W. Cottrell. 1979. Polysaccharides, p. 417-481. in H. J. Peppler and D. Perlman (ed.), Microbial technology: Microbial processes, 2nd ed., Vol. 1. Academic Press, Inc., New York.

Kolkman, M.A.B., B.A.M. van der Zeijst, and P. J. M. Nuitjens. 1997. Functional analysis of glycosyltransferases encoded by the capsular polysaccharide biosynthesis locus of Streptococcus pneumoniae serotype 14. J. Biol. Chem. 272:19502-19508.

Krauss, J., and R. Hakenbeck. 1997. A mutation in the D, D-carboxypeptidase penicillin-binding protein 3 of Streptococcus pneumon- 
iae contributes to cefotaxime resistance of the laboratory mutant C604. Antimicrob. Agents Chemother. 4:936-942.

Krinos, C. M., M. J. Coyne, K. G. Weinacht, A. O. Tzianabos, D.L. Kasper, and L. E. Comstock. 2001. Extensive surface diversity of a commensal microorganism by multiple DNA inversions. Nature 414:555-558.

Laws, A. P., and V. M. Marshall. 2001. The relevance of exopolysaccharides to the rheological properties in milk fermented with ropy strains of lactic acid bacteria. Int. Dairy J. 11:709-721.

Lazarevic, V., P. Margot, B. Soldo, and D. Karamata. 1992. Sequencing and analysis of the Bacillus subtilis lytRABC divergon: A regulatory unit encompassing the structural genes of the $\mathrm{N}$-acetylmuramoyl-L-alanine amidase and its modifier. J. Gen. Microbiol. 138:1949-1961.

Le Marrec, C., D. van Sinderen, L. Walsh, E. Stanley, E. Vlegels, S. Moineau, P. Heinze, G. Fitzgerald, and B. Fayard. 1997. Streptococcus thermophilus bacteriophages can be divided into two distinct groups based on mode of packaging and structural protein composition. Appl. Environ. Microbiol. 63:3246-3253.

Lemoine, J., F. Chirat, J.-M. Wieruszeski, G. Strecker, N. Favre, and J.-R. Neeser. 1997. Structural characterization of the exocellular polysaccharides produced by Streptococcus thermophilus SFi39 and SFi12. Appl. Environ. Microbiol. 63:3512-3518.

Levander, F., and P. Rädström. 2001. Requirement for phosphoglucomutase in exopolysaccharide biosynthesis in glucose- and lactoseutilizing Streptococcus thermophilus. Appl. Environ. Microbiol. 67:2734-2738.

Levander, F., M. Svensson, and P. Rådström. 2002. Enhanced polysaccharide production by metabolic engineering of Streptococcus thermophilus. Appl. Environ. Microbiol. 68:784-790.

Looijesteijn, P. J., L. Trapet, E. de Vries, T. Abee, and J. Hugenholtz. 2001. Physiological function of exopolysaccharides produced by Lactococcus lactis. Int. J. Food Sci. 64:71-80.

Low, D., J. A. Ahlgren, D. Horne, D. J. McMahon, C. J. Oberg, and J. R. Broadbent. 1998. Role of Streptococcus thermophilus MR-1C capsular exopolysaccharide on cheese moisture retention. Appl. Environ. Microbiol. 64:2147-2151.

Lucchini, S., F. Desiere, and H. Brussow. 1999. Comparative genomics of Streptococcus thermophilus phage species supports a modular evolution theory. J. Virol. 73:8647-8656.

Marshall, V. M., H. Dunn, M. Elvin, N. McLay, Y. Gu, and A. P. Laws. 2001a. Structural characterization of the exopolysaccharide produced by Streptococcus thermophilus EU20. Carbohydr. Res. 331:413-422.

Marshall, V. M., A. P. Laws, Y. Gu, F. Levander, P. Radstrom, L. De Vuyst, B. Degeest, F. Vaningelgem, H. Dunn, and M. Elvin. 2001b. Exopolysaccharide-producing strains of thermophilic lactic acid bacteria cluster into groups according to their EPS structure. Lett. Appl. Microbiol. 32:433-437.

McMahon, D. J., and C. J. Oberg. 1998. Influence of fat, moisture, and salt on functional properties of Mozzarella cheese. Aust. J. Dairy Technol. 53:98-101.

McMahon, D. J., C. J. Oberg, and W. McManus. 1993. Functionality of Mozzarella cheese. Aust. J. Dairy Technol. 48:99-104.

Mistry, V. V., and D. L. Anderson. 1993. Composition and microstructure of commercial full-fat and low-fat cheeses. Food Str. 12:259-266.

Moineau, S. 1999. Applications of phage resistance in lactic acid bacteria. Antonie van Leeuwenhoek. 76:377-382.

Moineau, S., M. Borkaev, B. J. Holler, S. A. Walker, J. K. Kondo, E. R. Vedamuthu, and P. A. Vanderbergh. 1996. Isolation and characterization of lactococcal bacteriophages from cultured buttermilk plants in the United States. J. Dairy Sci. 79:2104-2111.

Moineau, S., D. Tremblay, and H. Deveau. 2002. Does EPS protect LAB against phages? Proc. 97th Annual Meeting of the American Dairy Science Association. July 21 - 25. Québec City, Québec. J. Dairy Sci. 85 (suppl. 1).

Moineau, S., S. A. Walker, B. J. Holler, E. R. Vedamuthu, and P. A. Vandenbergh. 1995. Expression of a Lactococcus lactis phage resistance mechanism by Streptococcus thermophilus. Appl. Environ. Microbiol. 61:2461-2466.
Morona, J. K., R. Morona, D. C. Miller, and J. C. Paton. 2002. Streptococcus pneumoniae capsule biosynthesis protein $\mathrm{CpsB}$ is a novel manganese-dependent phosphotyrosine-protein phosphatase. J. Bacteriol. 184:577-583.

Morona, J. K., J. C. Paton, D. C. Miller, and R. Morona. 2000. Tyrosine phosphorylation of CpsD negatively regulates capsular biosynthesis in Streptococcus pneumonia. Mol. Microbiol. 35:1431-1442.

Nauth, K. R., and D. K. Hayashi. 1995. Method for manufacture of low-fat pasta filata cheese. US patent 5431931

Oberg, C. J., W. R. McManus, and D. J. McMahon. 1993. Microstructure of Mozzarella cheese during manufacture. Food Str. $12: 251-258$.

Perry, D. B., D. J. McMahon, and C. J. Oberg. 1997. Effect of exopolysaccharide-producing cultures on moisture retention in low-fat Mozzarella cheese. J. Dairy Sci. 80:799-805.

Petersen, B. L. 2001. Biochemistry and application of exopolysaccharide production in Mozzarella cheese starter cultures. MS Thesis, Utah State University, Logan.

Petersen, B. L., R. I. Dave, D. J. McMahon, C. J. Oberg, and J. R. Broadbent. 2000. Influence of capsular and ropy exopolysaccharide-producing Streptococcus thermophilus on Mozzarella cheese and cheese whey. J. Dairy Sci. 83:1952-1956.

Petit, C., J. P. Grill, N. Maazouzo, and R. Marczak. 1991. Regulation of polysaccharide formation by Streptococcus thermophilus in batch and in fed-batch cultures. Appl. Microbiol. Biotechnol. 36:216221.

Pluvinet, A., F. Charron-Bourgoin, C. Morel, and B. Decaris. 2000. Implication of horizontal transfers in the chimeric structure of the eps locus of Streptococcus thermophilus IP6757. GenBank accession number AJ289861.

Poolman, B. 1993. Energy transduction in lactic acid bacteria. FEMS Microbiol. Rev. 12:125-147.

Pruss, H.-D., and L.-W. Bahrs. 1981. Preparation of cheese with ropy lactic acid bacteria. US patent 4243684 .

Rahn, A., J. Drummelsmith, and C. Whitfield. 1999. Conserved organization in the cps gene clusters for expression of Escherichia coli group $1 \mathrm{~K}$ antigens: Relationship to the colanic acid biosynthesis locus and the cps genes from Klebsiella pneumoniae. J. Bacteriol. 181:2307-2313.

Rallu, F., P. Taillez, D. Ehrlich, and P. Renault. 2002. Common scheme of evolution between eps clusters of the food bacteria Streptococcus thermophilus and cps clusters of the pathogenic streptococci. Page 112 in Proc. 6th Am. Soc. Microbiol. Conf. on Streptococcal Genetics, Asheville, NC.

Rawson, H. L., and V. M. Marshall. 1997. Effect of 'ropy' strains of Lactobacillus delbrueckii ssp. bulgaricus and Streptococcus thermophilus on rheology of stirred yogurt. Int. J. Food. Sci. Technol. 32:213-220.

Reeves, P. R. 2002. Personal communication.

Reeves, P. R., M. Hobbs, M. A. Valvano, M. Skurnik, C. Whitfield, D. Coplin, N. Kido, J. Klena, D. Maskell, C. R. H. Raets, and P. D. Rick. 1996. Bacterial polysaccharide synthesis and gene nomenclature. Trends Microbiol. 4:495-503.

Roberts, I. S. 1996. The biochemistry and genetics of capsular polysaccharide production in bacteria. Annu. Rev. Microbiol. 50:285-315.

Robinson, D. K. 1981. Yogurt manufacture-some considerations of quality. Dairy Ind. Int. 46:31-35.

Saxelin, M.-L., E.-L. Nurmiaho, M. P. Korhola, and V. Sundman. 1979. Partial characterization of a new C3-type capsule-dissolving phage of Streptococcus cremoris. Can. J. Microbiol. 25:1182-1187.

Saxelin, M.-L., E.-L. Nurmiaho-Lassila, V. T. Meriläinen, and R. I. Forsén. 1986. Ultrastructure and host specificity of bacteriophages of Streptococcus cremoris, Streptococcus lactis subsp. diacetylactis and Leuconostoc cremoris from Finnish fermented milk "viili". Appl. Environ. Microbiol. 52:771-777.

Scholl, D., S. Rogers, S. Adhya, and C. R. Merril. 2001. Bacteriophage K1-5 encodes two different tail fiber proteins, allowing it to infect and replicate on both $\mathrm{K} 1$ and K5 strains of Escherichia coli. J. Virol. 75:2509-2515.

Sozzi, T., J. M. Poulin, R. Maret, and R. Pousaz. 1978. Isolation and some characteristics of phages of ropy strains of Streptococcus lactis. Milchwissenschaft 33:349-352. 
Stingele, F., J.-R. Neeser, and B. Mollet. 1996. Identification and characterization of the eps (exopolysaccharide) gene cluster from Streptococcus thermophilus Sfi6. J. Bacteriol. 178:1680-1690.

Stingele, F., J. W. Newell, and J.-R. Neeser. 1999. Unraveling the function of glycosyltransferases in Streptococcus thermophilus Sfi6. J. Bacteriol. 181:6354-6360.

Sutherland, I. W. 1972. Bacterial exopolysaccharides. Adv. Microb. Physiol. 8:143-212.

Sutherland, I. W. 2001. Microbial polysaccharides from Gram-negative bacteria. Int. Dairy J. 11:663-674.

Thomas, T. D., and V. L. Crow. 1984. Selection of galactose-fermenting Streptococcus thermophilus in lactose-limited chemostat cultures. Appl. Environ. Microbiol. 48:186-191.

Tunier, R. 1999. An exocellular polysaccharide and its interactions with proteins. Ph.D. Diss., Wageningen University, The Netherlands.

Vaillancourt, K., S. Moineau, M. Frenette, C. Lessard, and C. Vadeboncoeur. 2002. The galactose and lactose genes from the galactose-positive bacterium Streptococcus salivarius and the phylogenetically related galactose-negative bacterium Streptococcus thermophilus: Organization, sequence, transcription, and activity of the gal gene products. J. Bacteriol. 184:785-793.

Van Kranenburg, R., J. D. Marugg, I. I. van Swam, N. J. Willem, and W. M. de Vos. 1997. Molecular characterization of the plasmidencoded eps gene cluster essential for exopolysaccharide biosynthesis in Lactococcus lactis. Mol. Microbiol. 24:387-397.

Van Kranenburg, R., I. I. van Swam, J. D. Marugg, M. Kleerebezem, and W. M. de Vos. 1999a. Exopolysaccharide biosynthesis in Lactococcus lactis NIZO B40: Functional analysis of the glycosyltransferase genes involved in synthesis of the polysaccharide backbone. J. Bacteriol. 181:338-340.

Van Kranenburg, R., H. R. Vos, I. I. van Swam, M. Kleerebezem, and W. M. de Vos. 1999b. Functional analysis of glycosyltransferase genes from Lactococcus lactis and other gram-positive cocci: Complementation, expression, and diversity. J. Bacteriol. 181:63476353.

Vaughan, E. E., P. T. C. van den Bogaard, P. Catzeddu, O. P. Kuipers, and W. M. de Vos. 2001. Activation of silent gal genes in the lacgal regulon of Streptococcus thermophilus. J. Bacteriol. 183:1184-1194.
Vedamuthu, E. R., and J. M. Neville. 1986. Involvement of a plasmid in production of ropiness (mucoidness) in milk cultures by Streptococcus cremoris MS. Appl. Environ. Microbiol. 51:677-682.

Vincent, C., P. Doublet, C. Grangeasse, E. Vaganay, A. J. Cozzone, and B. Duclos. 1999. Cells of Escherichia coli contain a proteintyrosine kinase, Wzc, and a phosphotyrosine-protein phosphatase, Wzb. J. Bacteriol. 181:3472-3477.

Vincent, C., B. Duclos, C. Grangeasse, E. Vaganay, M. Riberty, A. J. Cozzone, and P. Doublet. 2000. Relationship between exopolysaccharide production and protein-tyrosine phosphorylation in gramnegative bacteria. J. Mol. Biol. 304:311-321.

Wang, L., D. Liu, and P. R. Reeves. 1996. C-terminal half of Salmonella enterica $\mathrm{WbaP}(\mathrm{RfbP})$ is the galactosyl-1-phosphate transferase domain catalyzing the first step of $\mathrm{O}$-antigen synthesis. J. Bacteriol. 178:2598-2604.

Welker, D. L., and J. R. Broadbent. 2002a. Streptococcus thermophilus strain MR-2C exopolysaccharide synthesis gene cluster. GenBank accession number AY061649.

Welker, D. L., and J. R. Broadbent. 2002b. Streptococcus thermophilus strain MTC360 exopolysaccharide synthesis gene cluster. GenBank accession number AF434993.

Welker, D. L., and J. R. Broadbent. 2002c. Streptococcus thermophilus strain MR-1C exopolysaccharide synthesis gene cluster. GenBank accession number AF448249.

Welker, D. L., C. J. Oberg, A. D. Cefalo, D. J. McMahon, and J. R. Broadbent. 2002a. Insight on the mechanism(s) for loss of exopolysaccharide synthesis phenotype in Streptococcus ther mophilus. Abstract P-8 in Proc. Ann. Mtg. Am. Soc. Microbiol.

Welker, D. L., K. R. Richards, C. C. Brown, and J. R. Broadbent. 2002b. Streptococcus thermophilus strain MTC310 exopolysaccharide synthesis gene cluster. GenBank accession number $\mathrm{AF} 448502$.

Whitfield, C., and W. J. Keenleyside. 1995. Regulation of expression of group IA capsular polysaccharides in Escherichia coli and related extracellular polysaccharides in other bacteria. J. Ind. Microbiol. 15:361-371.

Wugeditsch, T., A. Paiment, J. Hocking, J. Drummelsmith, C. Forrester, and C. Whitfield. 2001. Phosphorylation of Wzc, a tyrosine autokinase, is essential for assembly of group 1 capsular polysaccharides in Escherichia coli. J. Biol. Chem. 276:2361-2371.

Yother, J. 1999. Common themes in the genetics of streptococcal capsular polysaccharides. Pages 161-184 in J. B. Goldberg ed., Genetics of Bacterial Polysaccharides, CRC Press, New York. 